\title{
MS80, a novel sulfated oligosaccharide, inhibits pulmonary fibrosis by targeting TGF- $\beta 1$ both in vitro and in vivo
}

\author{
Han-dong JIANG ${ }^{1,2, *}$, Hua-shi GUAN ${ }^{1}$ \\ ${ }^{1}$ School of Medicine and Pharmacy, Ocean University of China, Qingdao 266003, China; ${ }^{2}$ Division of Respiratory Medicine, Affiliated \\ Hospital of Qingdao University, Qingdao 266071, China
}

\begin{abstract}
Aim: The pro-fibrogenic cytokine transforming growth factor-beta 1 (TGF- $\beta 1$ ) has attracted much attention for its potential role in the etiology of idiopathic pulmonary fibrosis (IPF). Here, we demonstrate that MS80, a novel sulfated oligosaccharide extracted from seaweed, can bind TGF- $\beta 1$. The aim of the present study was to determine whether MS80 is capable of combating TGF- $\beta 1-$ mediated pulmonary fibrotic events both in vitro and in vivo, and to investigate the possible underlying mechanisms.

Methods: Surface plasmon resonance was used to uncover the binding profiles between the compound and TGF- $\beta$. MTT assay, flow cytometry, Western blot analysis, BCA protein assay and SDS-PAGE gelatin zymography were used to probe the antifibrotic mechanisms of MS80. The in vivo fibrotic efficacy was evaluated in a bleomycin instillation-induced rat model.

Results: We report that MS80, a new kind of sulfated oligosaccharide extracted from seaweed, inhibits TGF- $\beta 1$-induced pulmonary fibrosis in vitro and bleomycin-induced pulmonary fibrosis in vivo. Our results indicated that MS80 competitively inhibited heparin/ HS-TGF- $\beta 1$ interaction through its high binding affinity for TGF- $\beta 1$. Moreover, MS 80 arrested TGF- $\beta 1$-induced human embryo pulmonary fibroblast (HEPF) cell proliferation, collagen deposition and matrix metalloproteinase (MMP) activity. Intriguingly, MS80 deactivated both the ERK and p38 signaling pathways. MS80 was also a potent suppressor of bleomycin-induced rat pulmonary fibrosis in vivo, as evidenced by improved pathological settings and decreased lung collagen contents.

Conclusion: MS80 in particular, and perhaps oligosaccharide in general, offer better pharmacological profiles with appreciably few side effects and represent a promising class of drug candidates for IPF therapy.
\end{abstract}

Keywords: sulfated oligosaccharide MS80; idiopathic pulmonary fibrosis; TGF- $\beta 1$

Acta Pharmacologica Sinica (2009) 30: 973-979; doi: 10.1038/aps.2009.86; published online 22 June 2009

\section{Introduction}

Idiopathic pulmonary fibrosis (IPF) remains a significant health problem that continues to increase in incidence and prevalence. It is typically progressive and leads to significant disability. The median survival ranges from 2 to 5 years from the time of diagnosis. Current medical therapies are ineffective in the treatment of IPF.

Recent studies have revealed that transforming growth factor- $\beta$ (TGF- $\beta$ ) is a master switch cytokine during $\operatorname{IPF}^{[1-4]}$. TGF- $\beta$ uses its chemotactic properties to recruit neutrophils and activate macrophages, which can secrete an array of cytokines, including TGF- $\beta$ itself ${ }^{[5]}$. These cytokines stimulate fibroblasts to secrete matrix proteins, mainly collagen. In

\footnotetext{
* To whom correspondence should be addressed.

E-mail jianghd@163.com

Received 2009-04-27 Accepted 2009-05-04
}

addition, TGF- $\beta$ can simultaneously decrease the production of matrix-degrading proteases, enhance the synthesis of protease inhibitors, and thus provide a non-degrading environment. By influencing important signals such as ERK and p38, TGF- $\beta$ can induce the excessive proliferation and accumulation of pulmonary fibroblasts and promote the synthesis and deposition of collagen, which plays a crucial role in fibrotic diseases $^{[6]}$. Among the three isoforms of TGF- $\beta$, TGF- $\beta 1$ has been the most widely studied to play a crucial role in the context of fibrogenesis. Therefore, TGF- $\beta 1$ appears to be a key downstream mediator of fibrogenesis in many organs and is an emerging target for the development of new and specific anti-fibrotic therapies ${ }^{[7-9]}$. Of the critical events mentioned above, heparin/heparan sulfate (HS) is particularly noted to contribute to TGF- $\beta$-mediated biological functions either by specifically binding to TGF- $\beta 1$, or by acting as a specific co-receptor for TGF- $\beta 1$ binding to its receptor. In fact, heparin/HS 
mediate TGF- $\beta 1$ availability by controlling the deposition of latent transforming growth factor- $\beta$-binding proteins (LTBPs) into the ECM in association with fibronectin. In this scenario, heparin/HS mimetics that target the TGF- $\beta$-heparin/HS interaction are thought to be promising candidates in IPF therapy.

With the availability of newly established TGF- $\beta$-based sensor-chip techniques in our laboratory, we found that MS80, a $8000 \mathrm{Da}$ sulfated oligosaccharide extracted from seaweed was a high-affinity TGF- $\beta$-binding agent. In the present study, we aimed to assess whether MS80 is capable of combating TGF- $\beta 1$-mediated pulmonary fibrotic events both in vitro and in vivo, and sought to elucidate the possible mechanisms of its action.

\section{Materials and methods Materials}

MS80 was prepared by Qingdao University. The structure of MS80 is shown in Figure 1. 3-(4,5-dimethylthiazol-2-yl)-2,5-diphenyl tetrazolium bromide (MTT) and propidium iodide (PI) were purchased from Sigma (St Louis, MO, USA). Dulbecco's modified Eagle's medium (DMEM) and trypsin were provided by Gibco (Invitrogen). Anti-phosphorylated p42/p44 (MAPK/ERK), anti-ERK1/2 (anti-p42/p44) mAb, anti-phosphorylated p38 MAPK (IgG), and goat anti-rabbit IgG conjugated to horseradish peroxidase were purchased from Cell Signaling Technology (Beverly, MA). TGF- $\beta 1$ was obtained from Peprotech EC, and sircol soluble collagen assay kit was purchased from Biocolor (Northern Ireland, UK). Human embryo pulmonary fibroblast (HEPF) cell line was purchased from Peking Union Medical Coll ge.

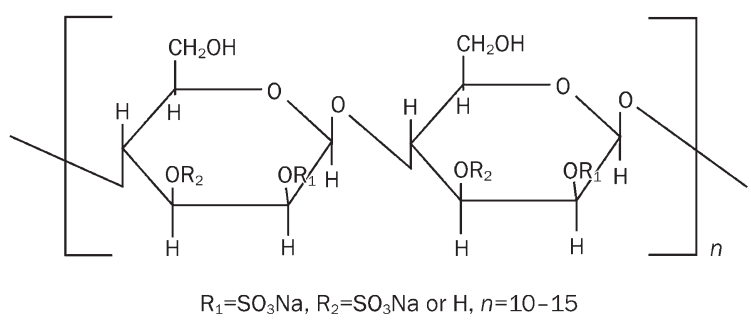

Figure 1. Chemical structure of MS80.

\section{Surface plasmon resonance assay}

To assess binding capacity of TGF- $\beta 1$ to MS80, biotinylated MS80 was immobilized on a CM5 sensor chip surface (BIAcore ${ }^{[10]}$. TGF- $\beta 1$ at various concentrations was injected over the sensor chip surface, followed by 5 min washing with PBS buffer. The sensor chip surface was regenerated using $2 \mathrm{~mol} / \mathrm{L} \mathrm{NaCl}$. To observe the inhibitory effect of MS80 on the binding of TGF- $\beta 1$ to heparin, the mixture of TGF- $\beta 1$ (200 $\mathrm{nmol} / \mathrm{L})$ and MS80 (0, 0.05, 0.1, 0.2, 0.4 , and $0.8 \mu \mathrm{g} / \mathrm{mL})$ was injected over the heparin-immobilized sensor chip surface. All binding experiments were performed at $25^{\circ} \mathrm{C}$ with a constant flow rate of $15 \mu \mathrm{L} / \mathrm{min}$ PBS. Sensorgrams for all binding interactions were recorded in real time and analyzed after subtract- ing the signal from the blank channel. Changes in mass due to the binding response were recorded as resonance units (RU). Binding kinetics and affinities were evaluated by SPR using BIAevaluation Software version 4.1.

\section{Bronchoalveolar lavage fluid harvest}

Rats were treated with bleomycin and on the seventh day; the tracheas were surgically exposed under sterile conditions and the lungs were lavaged through the trachea with a total of 3 $\mathrm{mL}$ of PBS. The bronchoalveolar lavage fluid was collected, centrifuged to remove any particles, divided and immediately frozen at $-80^{\circ} \mathrm{C}$.

\section{Cell culture and MTT assay}

HEPF cells were cultured in DMEM supplemented with 10\% fetal calf serum (FCS) in a humidified $5 \% \mathrm{CO}_{2}$ atmosphere at $37^{\circ} \mathrm{C}$. MS80 was dissolved in DMEM without FCS and the final concentration was adjusted to 25,50 , and $100 \mu \mathrm{g} / \mathrm{mL}$.

Cell proliferation was evaluated by the MTT assay. HEPF cells were plated in 96-well plates $\left(4.5 \times 10^{3}\right.$ cells/well) and incubated overnight. After being serum-starved for $24 \mathrm{~h}$, the cells were incubated for $48 \mathrm{~h}$ in the presence of BALF/ TGF- $\beta 1$ with or without MS80 (25, 50, and $100 \mu \mathrm{g} / \mathrm{mL})$. After incubation for $4 \mathrm{~h}$ with $100 \mu \mathrm{g} /$ well MTT, supernatants were removed and DMSO $(200 \mu \mathrm{L} /$ well $)$ was added. The plates were measured using a microwell plate reader at a wavelength of $570 \mathrm{~nm}$ and a reference wavelength of $630 \mathrm{~nm}$.

\section{Cell cycle analysis}

HEPF cell growth cycle change was measured using a flow cytometer (FCM). Cells were seeded in 6-well plates $\left(9 \times 10^{4}\right.$ cells/well), treated with TGF- $\beta 1$ as described above, and then harvested. Briefly, cells were trypsinized, centrifuged at 1500 $\mathrm{r} / \mathrm{min}$ for $5 \mathrm{~min}$ and washed with PBS twice. Then cells were incubated with PI for 30 min and analyzed with a flow cytometer.

\section{Collagen synthesis assay}

The effect of MS80 on BALF or TGF- $\beta 1$ induced collagen synthesis was measured with a sircol soluble collagen assay kit. HEPF cells were treated as described in the MTT assay and collagen levels were measured according to the manufacturer's instructions. Briefly, the supernatants and cell lysis products were centrifuged and collected. To each tube, $100 \mu \mathrm{L}$ of test sample and $1 \mathrm{~mL}$ Sircol Dye reagent were added and mixed for $30 \mathrm{~min}$. Then, the samples were centrifuged at $10000 \times g$ for $10 \mathrm{~min}$ and the unbound dye reagents were removed. The bound dye was released and dissolved for detection measurements. Protein quantities were measured with the BCA protein assay.

The collagen synthesis was calculated using collagen/total protein $(\%)$.

\section{MMP activity}

MMP activities were determined using SDS-PAGE gelatin zymography. Briefly, HEPF cells were treated with TGF- $\beta 1$ as 
above and the supernatants were concentrated with microcentrifugal filter devices at $4{ }^{\circ} \mathrm{C}$ and applied to $9 \%$ SDS polyacrylamide gels copolymerized with $0.1 \%$ gelatin. Then SDS was removed through a $30-\mathrm{min}$ incubation in $2.5 \%$ Triton X-100, and the gels were incubated in buffer $(20 \mathrm{mmol} / \mathrm{L}$ glycine, $\mathrm{pH}$ $8.3,10 \mathrm{mmol} / \mathrm{L} \mathrm{CaCl}_{2}, 1 \mu \mathrm{mol} / \mathrm{L} \mathrm{ZnCl}_{2}$ at $37^{\circ} \mathrm{C}$ ) for $24-36 \mathrm{~h}$. Gels were stained with Coomassie blue to visualize zones of gelatinolytic activity. The relative activities of MMPs were determined by densitometric analysis GeneTool (Syngene, Cambridge, United Kingdom).

\section{Western blot assay}

Western blot analysis was conducted using standard procedures. Briefly, HEPF cells $\left(9 \times 10^{4}\right.$ cells $\left./ \mathrm{mL}\right)$ were treated with or without TGF- $\beta 1$ after $12 \mathrm{~h}$ pre-exposure to MS80. Cells were harvested $30 \mathrm{~min}$ later and lysed in ice-cold lysis buffer (62.5 mmol/L Tris/ $\mathrm{HCl}, 2 \%$ SDS, 10\% glycerol, $50 \mathrm{mmol} / \mathrm{L}$ DTT, and $0.01 \%$ bromophenol). Proteins were separated by $10 \%$ SDS-PAGE and transferred to nitrocellulose membranes. Specific protein bands were detected with antibodies specific for corresponding proteins and HRP conjugated secondary antibody, and visualized by ECL reagents. The relative densities of phospho-ERK1/2 and phospho-p38 were determined by densitometric analysis GeneTool (Syngene, Cambridge, United Kingdom).

\section{Bleomycin instillation and in vivo study}

Pathogen-free adult Wistar rats weighing 200-230 g were purchased from the Drug Inspection Institute of Qingdao. Rats were divided into five groups with eight rats in each group. After a week for accommodation, rats were lightly anesthetized with phenobarbital sodium. Bleomycin at a dose of $5 \mathrm{mg} / \mathrm{kg}$ was reconstituted in saline solution and $0.05 \mathrm{~mL}$ volumes were instilled intratracheally into the lungs. Control animals only received sterile normal saline solution. MS80 was given once daily after bleomycin instillation by means of intragastric lavage at doses of 25,50 , and $100 \mathrm{mg} / \mathrm{kg}$. The animals were sacrificed 28 days after bleomycin administration. Left lungs were selected for collagen evaluation using the hydroxyproline assay kit. Right lungs were embedded in paraffin and stained with hematoxylin and eosin (HE) for histological and morphologic evaluations. Lesions were morphometrically evaluated in sections from each of the sampled lungs according to the technique of Bolender et al ${ }^{[11]}$.

\section{Data analysis}

Student's $t$-test and analysis of variance (ANOVA) were performed using Statview. $P<0.05$ was accepted as significant and $P<0.01$ was regarded as highly significant. All of the experiments were replicated at least three times.

\section{Results}

MS80 binds to TGF- $\beta 1$ with high affinity and competitively inhibits the interaction of TGF- $\beta 1$ with heparin

TGF- $\beta 1$-regulated function depends mostly on its association with cell surface heparin/heparan sulfate. We used surface plasmon resonance to examine the binding capacity of TGF- $\beta 1$ with MS80. Biotinylated MS80 was immobilized on a CM5 sensor chip surface (BIAcore) and then TGF- $\beta 1$, at various concentrations, was passed over the sensor chip surface to examine its binding capacity with MS80. Results showed that MS80 bound to TGF- $\beta 1$ in a concentration-dependent manner, with a $K_{\mathrm{D}}$ value of $0.597 \mu \mathrm{mol} / \mathrm{L}$ (Figure 2A). An additional competitive inhibition study demonstrated that MS80 significantly inhibited the association of TGF- $\beta 1$ with heparin in a concentration-dependent manner, with an $\mathrm{IC}_{50}$ of $0.39 \mu \mathrm{g} / \mathrm{mL}$ (Figure 2B). These results suggest that MS80 and heparin share overlapping binding site(s) with TGF- $\beta 1$.
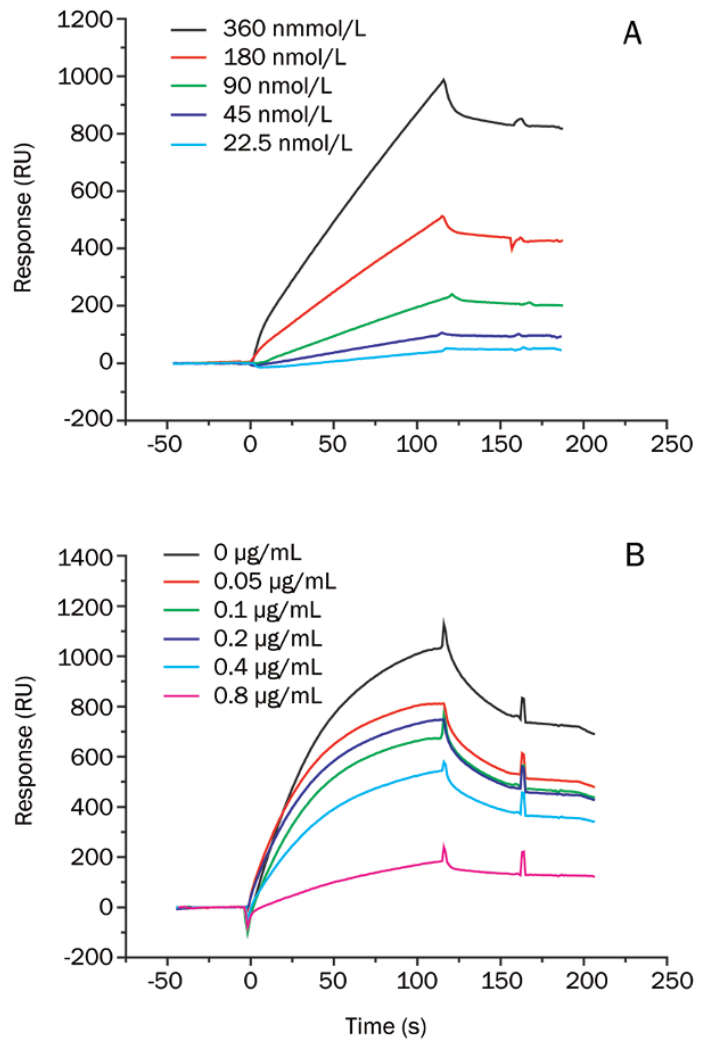

Figure 2. MS80 competitively inhibits the interaction between TGF- $\beta 1$ and heparin. (A) The interaction between MS80 and TGF- $\beta 1$ occurred in a concentration-dependent manner and the concentrations of TGF- $\beta 1$, from bottom to top, were 22.5, 45, 90, 180, and $360 \mathrm{nmol} / \mathrm{L}$. (B) Inhibitory effect of MS80 (from top to bottom: 0, 0.05, 0.1, 0.2, 0.4, and $0.8 \mu \mathrm{g} /$ $\mathrm{mL})$ on the binding of TGF- $\beta 1(200 \mathrm{nmol} / \mathrm{L})$ to heparin immobilized onto the biosensor chip surface. The experiment was carried out at $25^{\circ} \mathrm{C}$ with a flow rate of $15 \mu \mathrm{L} / \mathrm{min}$. The data are a representative of three independent experiments.

\section{MS80 inhibits TGF- $\beta 1$-dependent fibrogenic activity}

Since TGF- $\beta$-driven fibrogenesis greatly depends on TGF$\beta^{\prime}$ s heparin-binding properties ${ }^{[12]}$, we hypothesize that MS80 might be involved in TGF- $\beta 1$-driven pathological events. 
MS80 arrests TGF- $\beta 1$-induced cell proliferation and reverses the cell cycle

Fibroblast cell proliferation is an initial step of fibrogenesis which subsequently leads to IPF. To determine the effect of MS80 on TGF- $\beta 1$-induced cell proliferation, concentrationdependent studies of TGF- $\beta 1$ on cell proliferation were performed using the MTT assay. We found that TGF- $\beta 1$ induced concentration-dependent proliferation in HEPF cells, with the maximal effect observed at a concentration of $5 \mathrm{ng} / \mathrm{mL}$ (Figure
3A). Thus, this concentration was used for subsequent experiments.

Next, we assessed the effect of MS80 on TGF- $\beta 1$-induced cell proliferation. We found that MS80 at concentrations of 50 and $100 \mu \mathrm{g} / \mathrm{mL}$ significantly decreased TGF- $\beta 1$-induced cell proliferation (Figure 3B). Further cell cycle analysis revealed that TGF- $\beta 1$ could significantly drive the cells into $S$ phase, which was reversed by the addition of $100 \mu \mathrm{g} / \mathrm{mL}$ MS80 (Figure 3C).
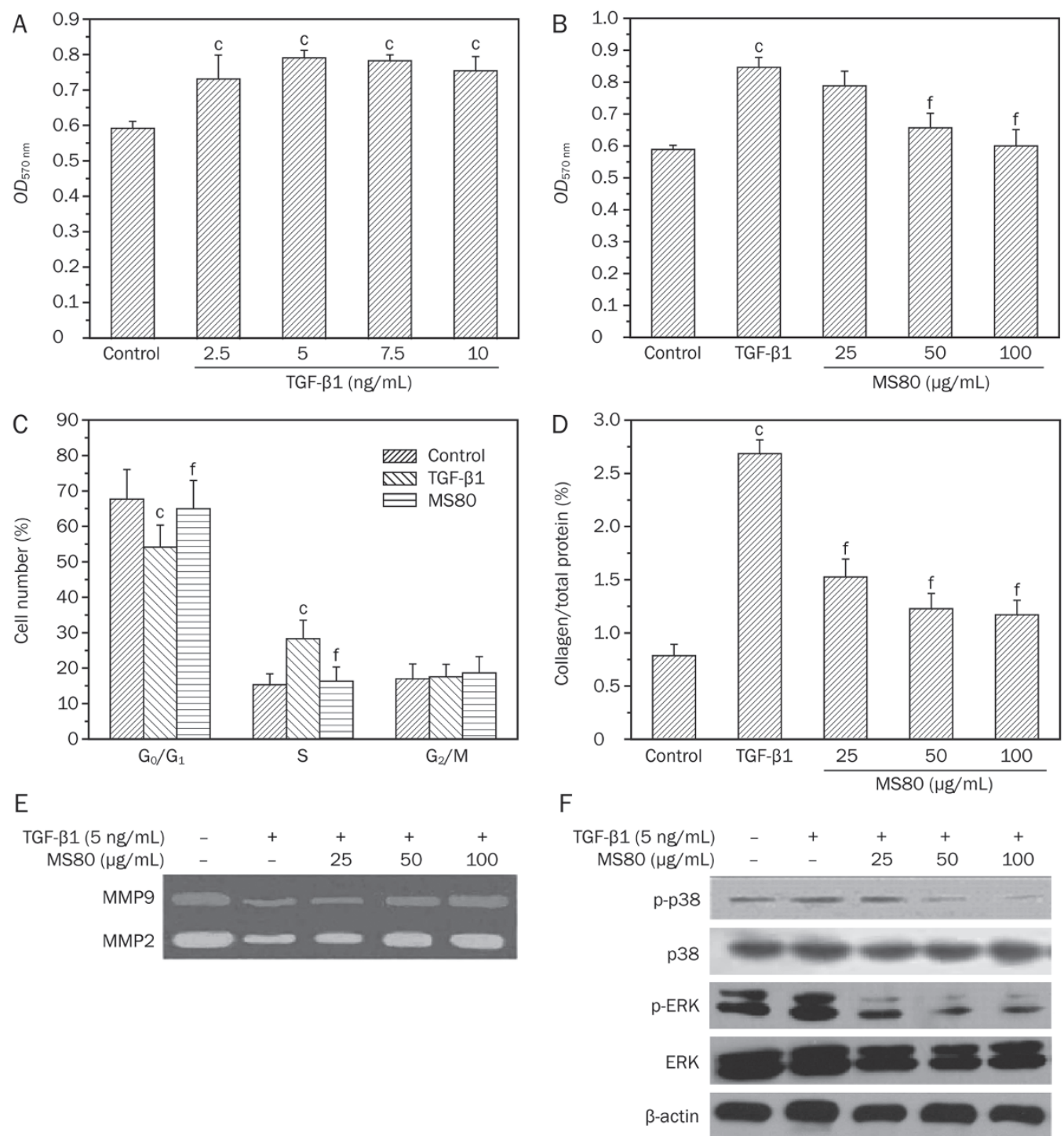

Figure 3. Effects of MS80 on TGF- $\beta 1$-induced fibrogenic activities. (A) Concentration-dependent effects of TGF- $\beta 1$ on HEPF proliferation. (B) Effects of MS80 on TGF- $\beta 1(5 \mathrm{ng} / \mathrm{mL})$ induced cell proliferation were examined with the MTT assay; (C) Effects of MS80 on cell cycle of TGF- $\beta 1$-treated HEPF cells. Serum-starved cells were seeded in 6-well plates and treated with TGF- $\beta 1(5 \mathrm{ng} / \mathrm{mL})$. After harvesting, the cells were incubated with PI for 30 min and analyzed with a flow cytometer. (D) Effect of MS80 on TGF- $\beta 1$-induced collagen synthesis. Serum-starved cells were treated with TGF- $\beta 1$ (5 ng/mL) and indicated concentrations of MS80 for $48 \mathrm{~h}$. Collagen levels were measured with the collagen assay kit and are presented as collagen/total protein (\%). (E) Effects of MS80 on TGF- $\beta 1$-induced MMP inhibition. The effect of MS80 on $5 \mathrm{ng} / \mathrm{mL}$ TGF- $\beta 1$ - induced MMP decrement was determined using SDS-PAGE gelatin zymography. (F) Effects of MS80 on the phosphorylation of ERK and p38 MAP kinase. The HEPF cells were seeded in 6-well plates $\left(9 \times 10^{4}\right.$ cells/well). Serum-starved cells were exposed for $12 \mathrm{~h}$ to MS80 $(0,25,50$, and $100 \mu \mathrm{g} / \mathrm{mL})$ then treated with or without TGF- $\beta 1$. Cells were then harvested, washed twice with cold PBS ( $\mathrm{pH} 7.4$ ) and lysed in $0.4 \mu \mathrm{L}$ sample buffer on ice for 30 min. Subsequently, cell lysates were subjected to Western blotting using phospho-specific, control ERK1/2, p38 and $\beta$-actin antibodies. Four parallel samples were prepared in each group. Data are shown as means $\pm \mathrm{SD}(n=4) .{ }^{\mathrm{c}} P<0.01$ vs control; ${ }^{\mathrm{f}} P<0.01$ vs TGF- $\beta 1$. 


\section{MS80 inhibits TGF- $\beta 1$-induced collagen synthesis}

Collagen synthesis/deposition represents one of the key features of IPF. To test the effect of MS80 on TGF- $\beta 1$-driven collagen synthesis, we used the BCA protein assay. We found that MS80 at given concentrations dramatically abrogated TGF- $\beta 1$ mediated collagen synthesis (Figure 3D).

\section{MS80 interferes with TGF- $\beta 1$-induced reduction of MMP activity}

In the late phase of IPF, fibroblasts migrate into the pulmonary alveoli and in particular, TGF- $\beta 1$-induced-collagen synthesis is always accompanied by a simultaneous decrease in MMP activity. To determine the effects of MS80 on TGF- $\beta 1$-induced MMP activity, we used SDS-PAGE gelatin zymography. We found that the TGF- $\beta 1$-treated group exhibited a reduced potency to lyse gelatin, which is indicative of a significant decrease in MMP activity. By contrast, MS80 at concentrations of 50 and $100 \mu \mathrm{g} / \mathrm{mL}$ increased gelatin lysis, suggesting the inhibitory action of MS80 towards TGF- $\beta 1$ reduced MMP activity (Figure 3E).

\section{MS80 inhibits TGF- $\beta 1$-induced $p 38$ and ERK signal activation}

The cross-talk between ERK and p38 is pivotal for TGF- $\beta 1$ induced collagen synthesis and MMP activity. Thus, we sought to address the involvement of MS80 in ERK and p38 signaling. Western blot analysis showed that MS80 at the concentrations of $50 \mu \mathrm{g} / \mathrm{mL}$ and $100 \mu \mathrm{g} / \mathrm{mL}$ suppressed TGF- $\beta 1$ induced p38 and ERK phosphorylation (Figure 3F), suggesting the involvement of p38 and ERK pathways in the inhibition of TGF- $\beta 1$ by MS80.

MS80 suppresses BALF-induced cell proliferation and collagen synthesis

Bleomycin-induced BALF is enriched with TGF- $\beta 1$. We next sought to examine the effect of MS80 against BALF-driven events. We found a dramatic increase in TGF- $\beta 1$ in bleomycin-induced BALF $(4.235 \pm 0.6653$ vs $1.326 \pm 0.0867 \mathrm{ng} / \mathrm{mL}$ of control), followed by a concentration-dependent induction of cell proliferation (Figure 4A). Of note, MS80 at concentrations of 50 and $100 \mu \mathrm{g} / \mathrm{mL}$ significantly abrogated BALF-induced cell proliferation (Figure 4B). In addition, $100 \mu \mathrm{L} /$ well BALF induced collagen synthesis, which was markedly reversed by MS80 at 50 and $100 \mu \mathrm{g} / \mathrm{mL}$ (Figure 4C). All of these data indicate that MS80 has the same inhibitory effects against BALFreleased TGF- $\beta 1$.

\section{MS80 inhibits pulmonary fibrosis in vivo}

Since MS80 exerted anti-fibrogenesis activities against both TGF- $\beta 1$ - and BALF-induced settings, we then sought to examine whether this effect can be recapitulated in vivo. For this, we used bleomycin-induced lung fibrosis in rats as a model. We found that bleomycin-treated rat lungs showed large changes in tissue structure associated with the infiltration of mononuclear cells, characterized by thickened and increased connective tissue in the intra-alveolar septa. In particular, numerous fibroblasts and myofibroblasts, together with collagen fibers, were found within the alveolar structure. In
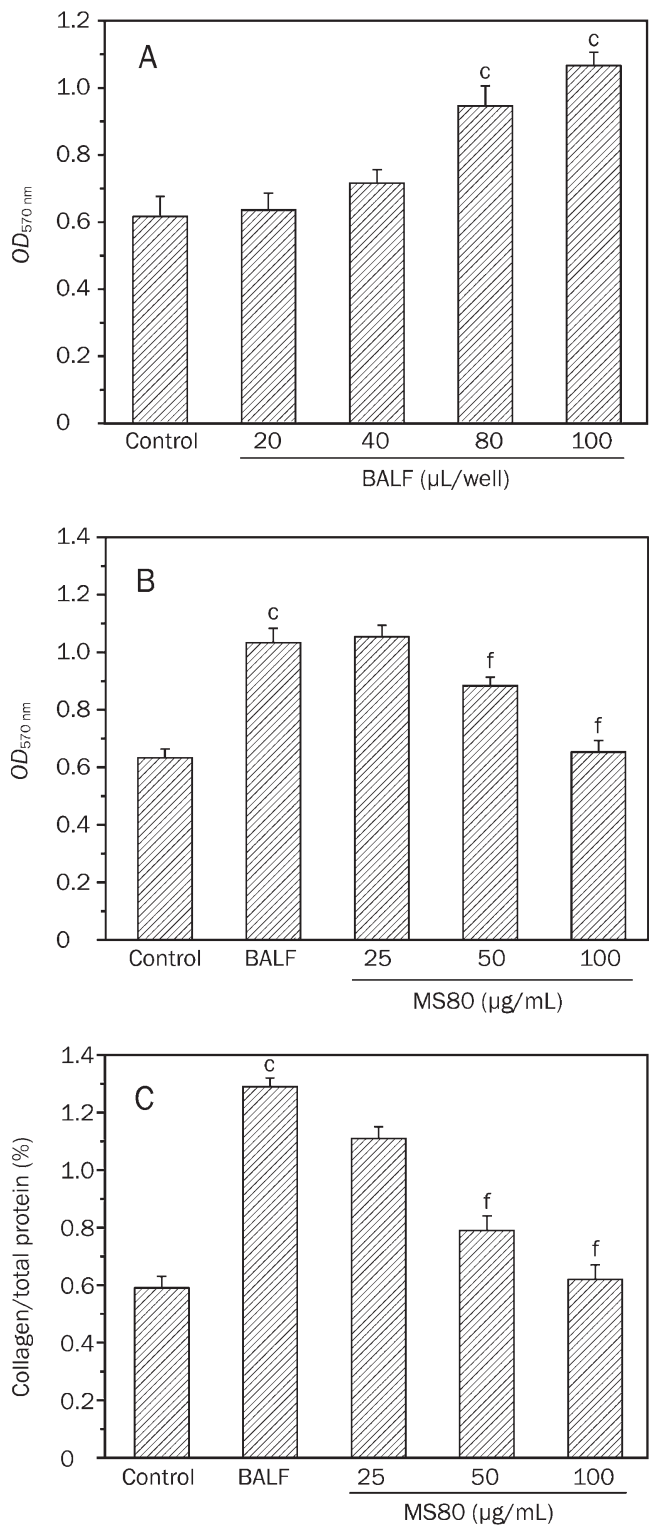

Figure 4. Effects of MS80 on BALF-induced HEPF proliferation and collagen synthesis. (A) Concentration-dependent effects of BALF on HEPF proliferation. (B) Effects of MS80 on BALF-induced cell proliferation were detected with the MTT assay. (C) Effect of MS80 on BALF-induced collagen synthesis. Serum-starved cells were treated with $100 \mu \mathrm{L} /$ well BALF and indicated concentrations of MS80 for $48 \mathrm{~h}$. The collagen was measured with the collagen assay kit and calculated using collagen/total protein (\%). Four parallel samples were prepared in each group. Data are shown as means $\pm \operatorname{SD}(n=4) .{ }^{c} P<0.01$ vs control; ${ }^{f} P<0.01$ vs BALF.

contrast, in MS80-treated lung tissues (50 and $100 \mathrm{mg} / \mathrm{kg}$ per day), there was less infiltration of inflammatory cells in alveolar spaces, accompanied by reduced thickness in alveolar walls and less deposition of collagen (Figure 5A). All of these results suggest that the oral administration of 50 and 100 $\mathrm{mg} / \mathrm{kg}$ MS80 significantly ameliorated bleomycin-induced impairment of lung tissue.

Further analysis revealed that there was a high level of 
A

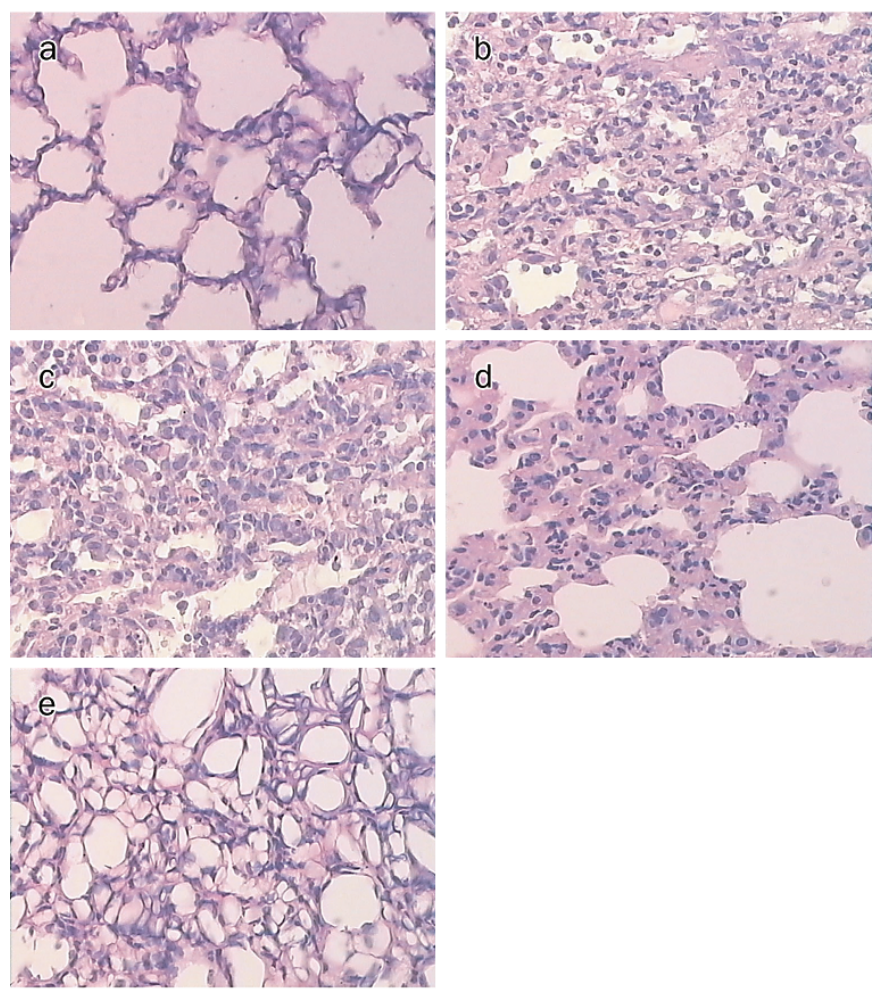

B

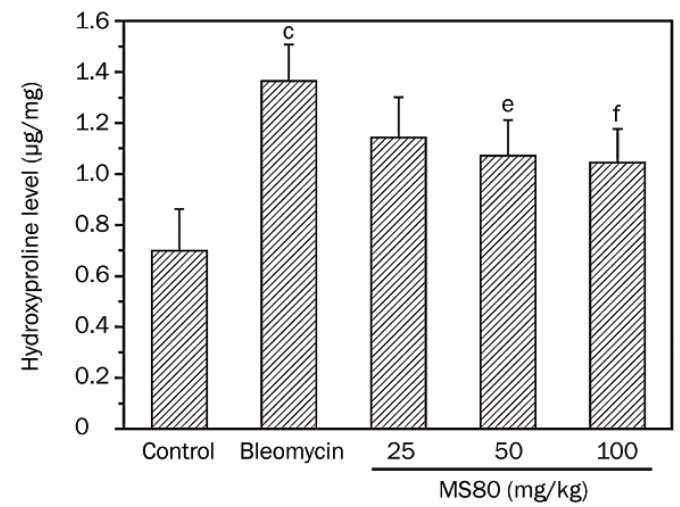

Figure 5. Effects of MS80 on pulmonary fibrosis in vivo. (A) Morphological evaluations of lungs were made by immunohistochemistry. a, control; b, bleomycin; c, d, e, MS80 of 25, 50, and $100 \mathrm{mg} / \mathrm{kg}$, respectively. (B) Hydroxyproline level of lungs were tested with a hydroxyproline assay kit. Eight parallel samples were prepared in each group and the data shown are representative of three independent experiments with similar results. Data are shown as means \pm SD $(n=8)$. ${ }^{\mathrm{c}} P<0.01$ vs control; ${ }^{e} P<0.05$, ${ }^{\mathrm{f}} P<0.01$ vs bleomycin.

hydroxyproline in bleomycin-treated lung tissues, which is the main component of collagen. However, MS80 at doses of 50 and $100 \mathrm{mg} / \mathrm{kg}$ significantly decreased the contents of hydroxyproline in lung tissues (Figure 5B), demonstrating the potent in vivo efficacy of MS80 against bleomycin-induced lung injury.

\section{Discussion}

IPF is a progressive disease of unknown etiology with high morbidity and mortality. Unfortunately, the current therapeutic repertoire to treat this disease is limited, nonspecific, and largely ineffective. In the present study, we demonstrated for the first time that MS80, a novel sulfated oligosaccharide, inhibits TGF- $\beta 1$-induced fibrogenic activity by binding to TGF- $\beta 1$, both in vitro and in a bleomycin-induced in vivo lung fibrosis rat model.

In the pathogenesis of fibrosis, TGF- $\beta 1$ has been implicated as a central profibrotic cytokine in IPF. The overexpression or dysregulation of TGF- $\beta 1$ leads to the development of fibrotic disorders by promoting cell proliferation, differentiation, and extracellular matrix production ${ }^{[13,14]}$. Moreover, TGF- $\beta 1$ can also regulate the activity of other cytokines, which in turn promotes fibrosis ${ }^{[13,15,16]}$. The involvement of heparin/HS in TGF- $\beta 1$-driven pathological events has also garnered much attention. In fact, heparin/HS contributes to the deposition of latent transforming growth factor- $\beta$-binding proteins (LTBPs) into the ECM either by specifically binding to TGF- $\beta 1$, or by acting as a co-receptor to assist TGF- $\beta 1$ in binding to its receptor. Thus, any heparin/HS mimetics blocking TGF$\beta 1$-associated events may be of great interest for novel IPF therapies ${ }^{[17]}$. Using the SPR assay, MS80 was found to competitively inhibit heparin-TGF- $\beta 1$ interaction in a concentrationdependent manner; the inhibition occurred via the direct binding of MS80 to TGF- $\beta 1$ with high affinity. All of these data suggest that MS80 might function as a competitive inhibitor for arresting the facilitative action of endogenous HS-TGF- $\beta 1$ complex. Indeed, MS80 inhibited TGF- $\beta 1$-induced cell proliferation, prevented TGF- $\beta 1$-driven collagen synthesis and reduced MMP activity. Similar effects recapitulated on BALFdriven events further support the hypothesis that MS80 inhibits fibrogenesis by targeting TGF- $\beta 1$.

TGF- $\beta 1$-induced fibrogenic events are strictly regulated by MAPK signaling pathways. Among these pathways, p38 and ERK1/2 are potent regulatory pathways with respect to type I and III collagen expression ${ }^{[18-20]}$. In this case, down-regulating p38 and ERK1/2 pathways are likely to be responsible for combating TGF- $\beta 1$-dependent biological activation. Here, our results show that MS80 potently depresses TGF- $\beta 1$-induced p38 and ERK1/2 activation, which subsequently underlies the regulatory action of MS80 on TGF- $\beta 1$-induced fibrogenesis.

Though no currently available animal model can fully represent interstitial pulmonary fibrosis pathology, bleomycininduced lung fibrosis is accepted as a surrogate interstitial pulmonary fibrosis model ${ }^{[21]}$. In our studies, we found that MS80 treatment could significantly suppress collagen deposition and improve the tissue structure of bleomycin-treated rat lungs. The nature of the in vivo anti-fibrosis action of MS80 in bleomycin-induced rat model is likely a result of the inhibitory action of MS80 against TGF- $\beta 1$-mediated events.

In sum, we show for the first time that MS80, a novel sulfated oligosaccharide, has both in vitro and in vivo anti-fibrotic effects, which may be attributed to the ability of MS80 to inhibit TGF- $\beta 1$-mediated pathological events via binding to 
TGF- $\beta 1$. More importantly, MS80 showed no toxicity at the concentrations used (data not shown). Continuing efforts to understand the structure-based mechanisms of MS80 in particular, and sulfated oligosaccharides in general, on pulmonary fibrosis will likely produce new insights into the development of novel oligosaccharide(s) for the treatment of IPF.

\section{Acknowledgements}

This work was supported by the National Natural Science Foundation of China (№ 30772884, 30271607).

\section{Author contribution}

Han-dong JIANG designed and performed the research, analyzed the data and wrote the manuscript. Hua-shi GUAN designed the research and wrote the manuscript.

\section{References}

1 Sime PJ, O'Reilly KM. Fibrosis of the lung and other tissues: new concepts in pathogenesis and treatment. Clin Immunol 2001; 99: 308-19.

2 Khalil N, O'Connor RN, Unruh HW, Warren PW, Flanders KC, Kemp A, et al. Increased production and immunohistochemical localization of transforming growth factor-beta in idiopathic pulmonary fibrosis. Am J Respir Cell Mol Biol 1991; 5: 155-62.

3 Coker RK, Laurent GJ. Anticytokine approaches in pulmonary fibrosis: bringing factors into focus. Thorax 1997; 52: 294-6.

4 Blobe GC, Schiemann WP, Lodish HF. Role of transforming growth factor beta in human disease. N Engl J Med 2000; 342: 1350-8.

5 Wahl SM, Hunt DA, Wakefield LM, McCartney-Francis N, Wahl LM, Roberts $\mathrm{AB}$, et al. Transforming growth factor type beta induces monocyte chemotaxis and growth factor production. Proc Natl Acad Sci USA 1987; 84: 5788-92.

6 Giri SN, Hyde DM, Hollinger MA. Effect of antibody to transforming growth factor beta on bleomycin induced accumulation of lung collagen in mice. Thorax 1993; 48: 959-66.

7 Grande JP. Role of transforming growth factor-beta in tissue injury and repair. Proc Soc Exp Biol Med 1997; 214: 27-40.

8 Cutroneo KR, White SL, Phan SH, Ehrlich HP. Therapies for bleomycin induced lung fibrosis through regulation of TGF-beta1 induced collagen gene expression. J Cell Physiol 2007; 211: 585-9.

9 Khan R. Examining potential therapies targeting myocardial fibrosis through the inhibition of transforming growth factor-beta 1. Cardiology 2007; 108: 368-80.

10 Li FC, Qi X, Geng MY. A novel method of immobilization of 911 for surface plasmon resonance biosensor. Chin J Anal Chem 2003; 31:
266-70.

11 Bolender RP, Hyde DM, Dehoff RT. Lung morphometry: a new generation of tools and experiments for organ, tissue, cell, and molecular biology. Am J Physiol 1993; 265 (6 Pt 1): L521-48.

12 Chen Q, Sivakumar P, Barley C, Peters DM, Gomes RR, FarachCarson MC, et al. Potential role for heparan sulfate proteoglycans in regulation of transforming growth factor-beta (TGF-beta) by modulating assembly of latent TGF-beta-binding protein-1. J Biol Chem 2007; 282: $26418-30$.

13 Fine A, Goldstein RH. The effect of transforming growth factor-beta on cell proliferation and collagen formation by lung fibroblasts. J Biol Chem 1987; 262: 3897-902.

14 Thannickal VJ, Lee DY, White ES, Cui Z, Larios JM, Chacon R, et al. Myofibroblast differentiation by transforming growth factor-beta1 is dependent on cell adhesion and integrin signaling via focal adhesion kinase. J Biol Chem 2003; 278: 12384-9.

15 Zhang XL, Topley N, Ito T, Phillips A. Interleukin-6 regulation of transforming growth factor (TGF)-beta receptor compartmentalization and turnover enhances TGF-beta1 signaling. J Biol Chem 2005; 280 : 12239-45.

16 Pantelidis P, Fanning GC, Wells AU, Welsh KI, Du Bois RM. Analysis of tumor necrosis factor-alpha, lymphotoxin-alpha, tumor necrosis factor receptor II, and interleukin-6 polymorphisms in patients with idiopathic pulmonary fibrosis. Am J Respir Crit Care Med 2001; 163 : 1432-6.

17 Wang Q, Wang Y, Hyde DM, Gotwals PJ, Koteliansky VE, Ryan ST, et al. Reduction of bleomycin induced lung fibrosis by transforming growth factor beta soluble receptor in hamsters. Thorax 1999; 54: 805-12.

18 Reunanen N, Foschi M, Han J, Kahari VM. Activation of extracellular signal-regulated kinase 1/2 inhibits type I collagen expression by human skin fibroblasts. J Biol Chem 2000; 275: 34634-9.

19 Tsukada S, Westwick JK, Ikejima K, Sato N, Rippe RA. SMAD and p38 MAPK signaling pathways independently regulate alpha1(I) collagen gene expression in unstimulated and transforming growth factor-betastimulated hepatic stellate cells. J Biol Chem 2005; 280: 10055-64.

20 Munshi HG, Wu YI, Mukhopadhyay S, Ottaviano AJ, Sassano A, Koblinski JE, et al. Differential regulation of membrane type 1-matrix metalloproteinase activity by ERK 1/2- and p38 MAPK-modulated tissue inhibitor of metalloproteinases 2 expression controls transforming growth factor-beta1-induced pericellular collagenolysis. J Biol Chem 2004; 279: 39042-50.

21 Westergren-Thorsson G, Hernnas J, Sarnstrand B, Oldberg A, Heinegard D, Malmstrom A. Altered expression of small proteoglycans, collagen, and transforming growth factor-beta 1 in developing bleomycin-induced pulmonary fibrosis in rats. J Clin Invest 1993; 92: 632-7. 